\title{
VINYL RADICAL INDUCED MICHAEL ADDITIONS: TOTAL SYNTHESIS OF
}

\author{
$( \pm)$-SEYCHELLENE
}

\section{K. VIJAYA BHASKAR and G.S.R. SUBBA RAO* \\ Department of Organic Chemistry, Indian Institute of science BANGALORE 560012 , INDIA}

Summary: A new strategy for the total synthesis of $(+)-$ seychellene which involves (i) a regiospecific construction of a bicyclö(2.2.2)octene moiety having a methyl group at the bridgehead and (i,i) a vinyl radical induced intramolecular Michael adeition is described.

Vinyl radical cyclisations have gained considerable importance for $^{1}$ the construction of carbocyclic rings in the design of complex organic molecules. The ability to capture these radicals on to suitable Michael acceptors will be of immense synthetic utility. We now report the use of a vinyl radical mediated Michael addition, for the construction of the tricyclic system (14) from the l-methylbicyclo (2.2.2) octene moiety (12) as exemplified (scheme 2) in the total synthesis of seychellene (1), a sesquiterpene which has been a target $^{2}$ for selectivity in synthetic design.

The bicyclol 2.2.2) loctenes having a methyl group at the bridgehead with appropriate substituents are readily constructed from dihydrobenzoic acids (Scheme 1). Thus cycloaddition of the diene acid (4), obtained from m-toluic acid(2) through the unconjugated acid (3) with methyl vinyl ketone (MVK) resulted in the regiospecific formation of the endo-adduct ${ }^{3}$ (5) which was converted into the ester (10) through pyrolysis 4 of the pyrazolone (6). Alternatively the compound (10) was directly obtained by the reaction of methyl 1,2-dimethylcyclohexa-1,3-diene-3-carboxylate (9) prepared from 2,3dimethylbenzoic acid (7) through the dihydroacid (8) with MVK.

This exclusive formation of a single regio-adduct in these cycloadations clear ly demonstrates the directing influence of the methyl group over the carboxyl substituent and will be of interest in the synthesis of bridged bicyclo(2.2.2)octenes having a methyl group at the apex. 


\section{SCHEME 1}
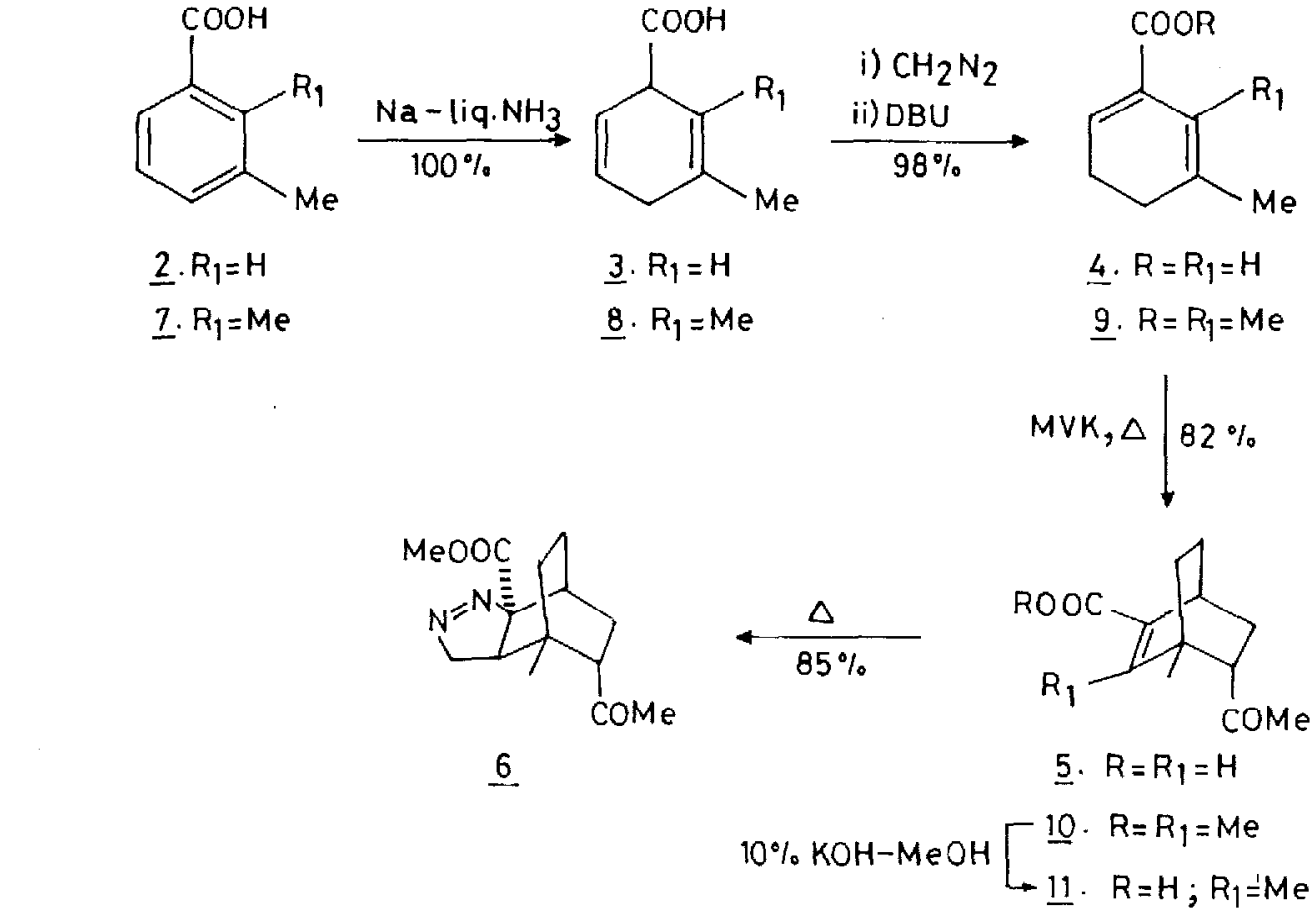

Attempts to convert the keto acid (11) to the tricyclic system involving an allyl radical mediated intramolecular Michael reaction under variety of conditions was unsuccessful (Scheme II). Hence a more flexible route involving the vinyl radical mediated Michael reaction was attempted.

\section{SCHEME II}

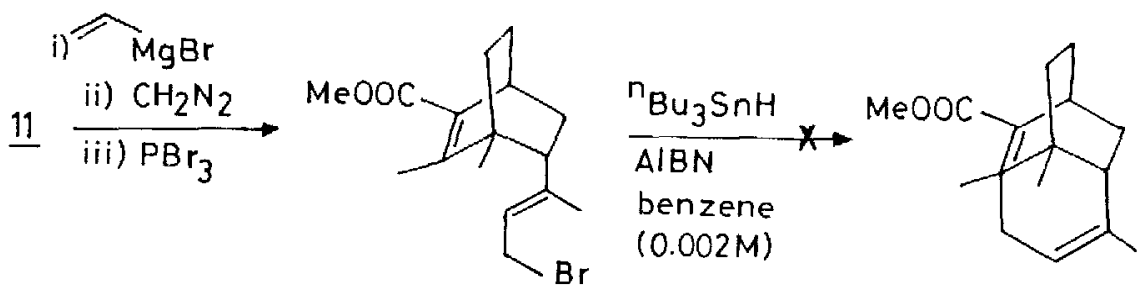

Reaction of the acid (Il) with propargyl magnesium bromide in THF,followed by esterification, gave the acetylenic ester (12). Treatment of (12) with tributyl tin hydride in refluxing benzene afforded ${ }^{5}$ the stannane deriva- 
tive (13) which was found to be partially converted ${ }^{6}$ into (14) on chromatography over silica gel. Oxidation of the mixture of (13) \& (14) with Ruo 4 ' generated in situ ${ }^{7}$, yielded the tricyclic hydroxy ketoester (15), smoothly dehyarated ${ }^{8}$ to the unsaturated keto ester (16). Catalytic hydrogenation of (16) afforded exclusively the product (17) having the expected ${ }^{9}$ equatorial methyl group. Direct reduction of (17) to (20) was attempted but was unsuccessful due to the steric hinderence of the carbonyl group. The $r$-keto ester was reduced with $\mathrm{NaBH}_{4}$ leading to the $\Upsilon_{\text {-lactone }}{ }^{0}(18)$. Treatment of the lactone (18) with $\mathrm{SOCl}_{2} / \mathrm{MeOH}$ furnished the unsaturated ester (19) hydrogenated catalytically to the saturated ester (20). Reduction of 20 with

SCHEME III

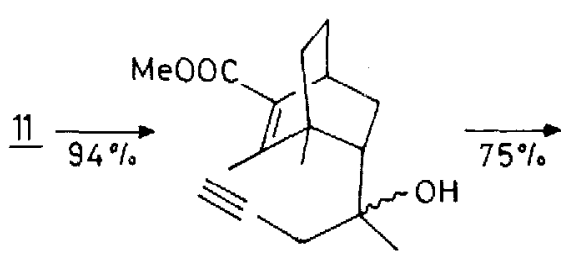

12

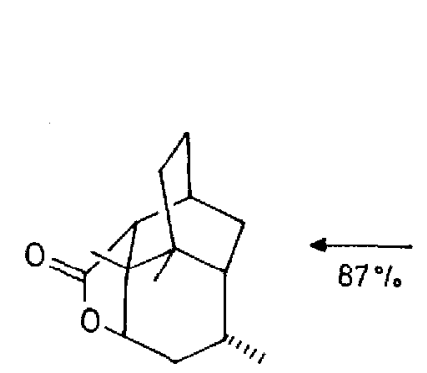

18 $90 \%$

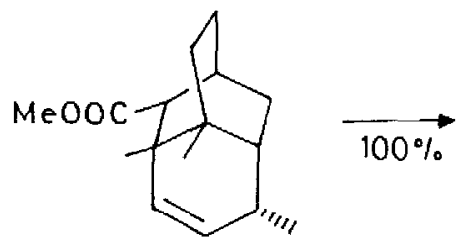

19<smiles>[R]C=C1CC2(C)CC3CCC(CC(C(C)=O)C3(C)C2)C1(C)O</smiles>

13. $R=5 n \mathrm{Bu}_{3}$

14. $\mathrm{R}=\mathrm{H}$

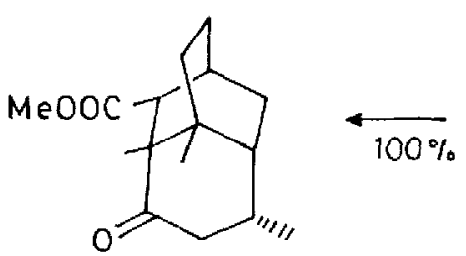

17

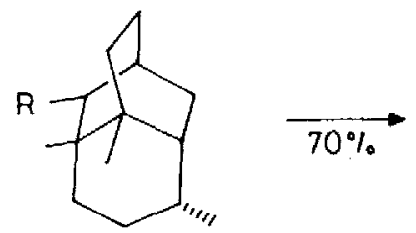

$92 \%\left[\begin{array}{ll}\text { 20 } & \mathrm{R}=\mathrm{COOMe} \\ 21 & \mathrm{R}=\mathrm{CH}_{2} \mathrm{OH}\end{array}\right.$

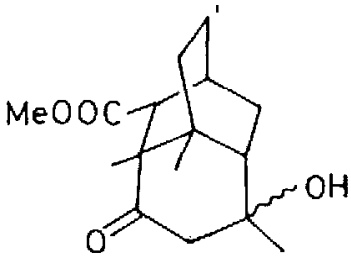

15<smiles>O[C@H]1[C+]CC1</smiles><smiles>CC(=O)C1C2CCC(C)(C(=O)C=C2C)C1(C)C</smiles>

16

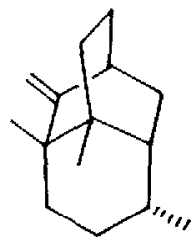

1 
LAH afforded the alcoholl0 (21) which could be readily dehydratedil to seychellene (1), identified by comparison with an authentic sample. The compounds (18) and (2I) were also compared with those obtained 10 from seychellene to establish their identity.

Further applications of the demonstrated utility of this synthetic strategy involving the construction of a highly tunctionalised bicyclo(2.2.2)octene derivative from a cyclohexadiene acid and its elaboration to seychellene through vinyl radical assisted intramolecular Michael addition to other complex structures are currently underway in our laboratory.

Acknowledgements: We thank Professor Gourisson, CNRS, Gif sur yvette, France for a sample of seycheijene and the DST for support of this investigation. KVB thanks the csir for a fellowship.

\section{References}

1. M. Ramaiah, Tetrahedron, 43, 3541 (1987).

2. G.Stork, N.H. Baine, Tetrahedron Lett., 5927 (1985).

3. All new compounds reported have been fully characterised on the basis of their spectral data (IR, ${ }^{1}$ H NR, ${ }^{13}$ C NMR and Mass spectra) and elemental analysis.

4. C.Cativiela,M.D. Diazde Villegas, J.A. Mayoral, E. Melendez, J.org.Chem..., 50ㅇ 3167 (1985).

5. N.N. Marinoic, H. Ramanathan, Tetrahedron Lett., 1871 (1983).

6. G. Stork, R. Mook, J.Am.Chem.Soc., lug, 2829 (1987).

7. P.H. Carlson, T. Katsuki, V.S. Maruti, K.B. Sharpless, J.org.Chem., 46, $3936(1981)$.

8. F. D'onofrio, A. Scettri, Synthesis, 1159 (1985).

9. E. Piers, R.W. Britton, W. de wal, J.All.chem.Soc., 93, 5113 (1973).

10. G. Wolff, G. Ourisson, Tetrahedron, 25, 4903 (1969).

11. R.M. Williams, L.K.Maruyama, J.org.Chem., 52, 4044 (1987).

(Received in UK 21 November 1988) 